\title{
PENENTUAN TINGKAT RESIKO PENYAKIT DIABETES MELLITUS DENGAN METODE SUGENO DI RSUD UNDATA PROVINSI SULAWESI TENGAH
}

\author{
Huzaimah¹, S. Musdalifah², A. Hendra ${ }^{3}$, I. W. Sudarsana ${ }^{4}$ \\ 1,2,4 Prodi Matematika Jurusan Matematika FMIPA UNTAD \\ 3Jurusan Tekhnik Informatika Fakultas Tekhnik UNTAD \\ Kampus Bumi Tadulako Tondo \\ Jl.Soekarno Hatta Km.9, Palu, 94118, Indonesia \\ 1Hestyiana.rifai@ymail.com, 2selvymusdalifah@yahoo.com, 3a_for_andie@icloud.com, \\ ${ }^{4}$ sudarsanaiwayan@yahoo.co.id
}

\begin{abstract}
Abstrak
Logika Fuzzy adalah suatu cara yang tepat untuk memetakan suatu ruang input ke dalam suatu ruang output. Salah satunya adalah dalam penentuan tingkat resiko penyakit (diagnosa penyakit).Dengan bantuan FIS (Fuzzy Inference System) pada model Sugeno, dapat diperoleh hasil perkiraan diagnosa untuk seorang pasien terhadap suatu tingkat penyakit dengan memperhatikan gajala-gajala penyakit Diabetes Mellitus. Metode Sugeno mempunyai tahapan proses yaitu (a) pembentukan himpunan Fuzzy (b) aplikasi fungsi implikasi (c) komposisi aturan (d) penegasan (defuzzifikasi) dengan menggunakan nilai rata-rata. Hasil penelitian dari ke-10 sampel pasien, ada 6 pasien yang Negatif Diabetes Mellitus, 1 pasien Pradiabetes dan 3 pasien Positif Diabetes Mellitus. Faktor penyebab utama terjadinya tingkat resiko penyakit Diabetes Mellitus pada pasien tersebut adalah Gula Darah Puasa yang tinggi.
\end{abstract}

Kata kunci $\quad$ : Logika Fuzzy, Metode Sugeno, Fuzzy Inference System, Tingkat Resiko Penyakit.

\section{Pendahuluan}

Menurut World Health Organization (WHO) 1980 menyatakan bahwa Diabetes Mellitusmerupakan suatu yang tidak dapat dituangkan dalam satu jawaban yang jelas dan singkat tetapi secara umum dapat dikatakan sebagai suatu kumpulan problema anatomik dan kimiawi yang merupakan akibat dari sejumlah faktor di mana didapat defisiensi insulin absolut atau relatif dan gangguan fungsi insulin (Soegondo, 2004).

Klasifikasi etiologis Diabetes Mellitus menurut ADA 2005 yaitu Diabetes Mellitus tipe 1, Diabetes Mellitus tipe 2, Diabetes Mellitus tipe lain dan Diabetes Kehamilan (Gestasional). Di Indonesia jumlah keseluruhan kasus penyakit Diabetes Mellitus tipe 1 belum diketahui secara pasti, 
tipe ini jarang ditemui. Hal ini disebabkan karena Indonesia terletak di khatulistiwa atau faktor genetik yang tidak mendukung. Lain halnya pada Diabetes Mellitus tipe 2 yang meliputi lebih dari $90 \%$ dari jumlah populasi penderita Diabetes untuk selanjutnya disebut diabetesi, faktor lingkungan sangat berperan (Sudoyo, 2006).

Indonesia menjadi negara keempat di dunia yang memiliki angka diabetesi terbanyak. Diabetesi secara keseluruhan di Indonesia mengalami peningkatan hingga 14 juta orang (DetikNews, 15 April 2007). Hal ini berdasarkan laporan dari WHO, dimana pada jumlah Diabetesi di Indonesia pada tahun 2000 adalah 8,4 juta orang setelah India (31,7 juta), Cina (20,8 juta) dan Amerika Serikat (17,7 juta). Diperkirakan jumlah tersebut akan meningkat pada tahun 2030, India (79,4 juta), Cina (42,3 juta), Amerika Serikat (30,3 juta) dan Indonesia (21,3 juta) (Darmono, 2005).

Peningkatan jumlah Diabetesidisebabkan keterlambatan penegakan diagnosis penyakit tersebut. Pasien sudah meninggal akibat kompikasi sebelum adanya penegakan diagnosis (Sudoyo, 2006). Penyebab keterlambatan penegakan diagnosis tersebut adalah banyaknya faktor yang berpengaruh terhadap pilihan-pilihan yang ada atau beragamnya variabel. Logika Fuzzy dengan Metode Sugenomerupakan salah satu solusi untuk mengatasi masalah tersebut. Sebab konsep logika Fuzzysangat fleksibel dan mudah dimengerti.

\section{Metode Penelitian}

Berikut adalah penjelasan dari tahapan penelitian yang akan dilakukan penyusun dalam proses penelitian :

1. Memulai Penelitian

2. Melakukan studi literatur dengan mengumpulkan materi dari buku-buku, artikel dan jurnal yang di dapat dari perpustakaan dan perpustakaan online.

3. Mengkonfirmasi ke Dokter mengenai gejala-gajala penyakit yang akan diteliti.

4. Mengambil data.

5. Menentukan input dan output Fuzzy berdasarkan fungsi keanggotaannya.

6. Menentukan aturan Fuzzy berdasarkan kombinasi dari himpunan Fuzzy setiap variabel input.

7. Membuat aplikasi fungsi implikasi, komposisi aturan, dan defuzzyfikasi sebagai langkah untuk melakukan inferensi sistem Fuzzy pada sebuah contoh kasus

8. Menyimpulkan hasil penelitian.

9. Selesai. 


\section{Hasil dan Pembahasan}

\subsection{Hasil}

3.1.1. Mengkonfirmasi Gejala - gajala Penyakit

Tabel 1 : Hasil Wawancara tentang Gejala-gajala DM dan batas nilai normal.

\begin{tabular}{|c|l|c|}
\hline No & \multicolumn{1}{|c|}{ Variabel Fuzzy } & Nilai Normal \\
\hline 1 & GulaDarahPuasa & $80-120(\mathrm{mg} / \mathrm{dl})$ \\
\hline 2 & Gula Plasma Puasa & $70-100(\mathrm{mg} / \mathrm{dl})$ \\
\hline 3 & Gula Plasma Tidur & $110-150(\mathrm{mg} / \mathrm{dl})$ \\
\hline 4 & GulaDarah 2 jam PP & $100-140(\mathrm{mg} / \mathrm{dl})$ \\
\hline 5 & Kadar HbA1c & $4-8(\mathrm{mg} / \mathrm{dl})$ \\
\hline 6 & Kadar HDL & $40-60(\mathrm{mg} / \mathrm{dl})$ \\
\hline 7 & Kadar Trigliserida & $50-150(\mathrm{mg} / \mathrm{dl})$ \\
\hline 8 & Kadar Insulin & $4-8(\%)$ \\
\hline
\end{tabular}

3.1.2. Menentukan Variabel Fuzzy beserta Fungsi Keanggotaannya

Tabel 2 : Variabel dan Himpunan Fuzzy tentang gejala-gajala DM

\begin{tabular}{|c|c|c|c|c|}
\hline Fungsi & Nama Variabel & $\begin{array}{c}\text { Nama Himpunan } \\
\text { Fuzzy }\end{array}$ & $\begin{array}{c}\text { Semesta } \\
\text { pembicaraan }\end{array}$ & Keterangan \\
\hline \multirow{4}{*}{$x_{1}$} & \multirow{4}{*}{ Gula Darah Puasa } & Rendah & \multirow{4}{*}[75-155]{} & $75-85$ \\
\hline & & Sedang & & $75-125$ \\
\hline & & Tinggi & & $115-155$ \\
\hline & & Sangat Tinggi & & $145-155$ \\
\hline \multirow{4}{*}{$x_{2}$} & \multirow{4}{*}{ Gula Plasma Puasa } & Rendah & \multirow{4}{*}{ [65 -145] } & $65-75$ \\
\hline & & Sedang & & $65-115$ \\
\hline & & Tinggi & & $105-145$ \\
\hline & & Sangat Tinggi & & $135-145$ \\
\hline \multirow{3}{*}{$x_{3}$} & \multirow{3}{*}{ Gula Plasma Tidur } & Rendah & \multirow{3}{*}{ [105 - 155] } & $105-115$ \\
\hline & & Sedang & & $105-155$ \\
\hline & & Tinggi & & $145-155$ \\
\hline \multirow{4}{*}{$x_{4}$} & \multirow{4}{*}{ Gula Darah 2 Jam PP } & Rendah & \multirow{4}{*}{ [95 - 205] } & $95-105$ \\
\hline & & Sedang & & $95-145$ \\
\hline & & Tinggi & & $135-205$ \\
\hline & & Sangat Tinggi & & $195-205$ \\
\hline
\end{tabular}




\begin{tabular}{|c|c|c|c|c|}
\hline \multirow{3}{*}{$x_{5}$} & \multirow{3}{*}{ Kadar $\mathrm{HbA} 1 \mathrm{c}$} & Rendah & \multirow{3}{*}{ [3 - 7] } & $3-4$ \\
\hline & & Sedang & & $3-6$ \\
\hline & & Tinggi & & $6-7$ \\
\hline \multirow{3}{*}{$x_{6}$} & \multirow{3}{*}{ Kadar HDL } & Rendah & \multirow{3}{*}{ [35 - 65] } & $35-45$ \\
\hline & & Sedang & & $35-65$ \\
\hline & & Tinggi & & $55-65$ \\
\hline \multirow{3}{*}{$x_{7}$} & \multirow{3}{*}{ Kadar Trigliserida } & Rendah & \multirow{3}{*}{ [45 - 155] } & $45-55$ \\
\hline & & Sedang & & $45-155$ \\
\hline & & Tinggi & & $145-155$ \\
\hline \multirow{3}{*}{$x_{8}$} & \multirow{3}{*}{ Kadar Insulin } & Rendah & \multirow{3}{*}[3-7]{} & $3-4$ \\
\hline & & Sedang & & $3-6$ \\
\hline & & Tinggi & & $6-7$ \\
\hline
\end{tabular}

3.1.3. Menentukan aturan Logika Fuzzy dalam penentuan tingkat resiko Penyakit Diabetes Mellitus [R1] IF GDP rendah AND GPT rendah THEN Negatif Diabetes [R2] IF GDP rendah AND GPP rendah THEN Negatif Diabetes [R3] IF GDP rendah AND GD rendah THEN Negatif Diabetes [R4] IF GDP rendah AND HDL sedang THEN Negatif Diabetes [R5] IF GDP rendah AND HbAlc rendah THEN Negatif Diabetes [R6] IF GDP rendah AND Tg rendah THEN Negatif Diabetes [R7] IF GDP rendah AND Insulin sedang THEN Negatif Diabetes [R8] IF GPT rendah AND GPP rendah THEN Negatif Diabetes [R9] IF GPT rendah AND GD rendah THEN Negatif Diabetes [R10] IF GPT rendah AND HDL sedang THEN Negatif Diabetes [R11] IF GPT rendah AND HbA1c rendah THEN Negatif Diabetes [R12] IF GPT rendah AND Tg rendah THEN Negatif Diabetes [R13] IF GPT rendah AND Insulin sedang THEN Negatif Diabetes [R14] IF GPP rendah AND GD rendah THEN Negatif Diabetes [R15] IF GPP rendah AND HDL sedang THEN Negatif Diabetes [R16] IF GPP rendah AND HbA1c rendah THEN Negatif Diabetes [R17] IF GPP rendah AND Tgrendah THEN Negatif Diabetes [R18] IF GD rendah AND HDL sedang THEN Negatif Diabetes [R19] IF GD rendah AND HbA1c rendah THEN Negatif Diabetes [R20] IF GD rendah AND Tg rendah THEN Negatif Diabetes [R21] IFHbA1c rendah AND HDL sedang THEN Negatif Diabetes [R22] IF HbA1c rendah AND Tg rendah THEN Negatif Diabetes 
[R23] IF GDP sedang AND GPT sedang THEN Pradiabetes

[R24] IF GDP sedang AND GPP sedang THEN Pradiabetes

[R25] IF GDP sedang AND GD tinggi THEN Pradiabetes

[R26] IF GDP tinggi AND Insulin rendah THEN Positif Diabetes Tipe 1

[R27] IF GDP sangat tinggi AND Insulin rendah THEN Positif Diabetes Tipe 1

[R28] IF Umur Anak AND Insulin rendah THEN Positif Diabetes Tipe 1

[R29] IF HbA1c tinggi AND Insulin rendah THEN Positif Diabetes Tipe 1

[R30] IF Umur Dewasa AND GDP tinggi THEN Positif Diabetes Tipe 2

[R31] IF GDP sangat tinggi AND HDL rendah THEN Positif Diabetes Tipe 2

[R32] IF HbA1c tinggi AND HDL rendah THEN Positif Diabetes Tipe 2

[R33] IF HbA1c tinggi AND Tg tinggi THEN Positif Diabetes Tipe 2

3.1.4. Membuat aplikasi fungsi implikasi, komposisi aturan, dan defuzzyfikasi sebagai langkah untuk melakukan inferensi sistem Fuzzypada salah seorang pasien.

a. Pasien

Seorang pasien usia 19 tahun memiliki hasil pemeriksaan laboratorium :

Glukosa Darah Puasa (GDP) $69 \mathrm{mg} / \mathrm{dl}$

Glukosa Plasma Puasa (GPP) $61 \mathrm{mg} / \mathrm{dl}$

Glukosa Plasma Tidur (GPT) $105 \mathrm{mg} / \mathrm{dl}$

Glukosa Darah 2 jam PP (GD) 109 mg/dl

Kadar HbA1c 6 mg/dl

Kadar HDL 50 mg/dl

Trigliserida $111 \mathrm{mg} / \mathrm{dl}$

Kadar Insulin 4 \%

maka nilai keanggotaan fungsi pada tiap-tiap himpunan berdasarkan fungsi keanggotaan :

$>\quad$ Glukosa Darah Puasa (GDP)

$\mu_{\mathrm{GDPrendah}}\left[\mathrm{x}_{1}\right][69]=1$

$\mu_{\text {GDPsedang }}\left[\mathrm{x}_{1}\right][69]=1$

$\mu_{\text {GDPsangat tinggi }}\left[\mathrm{x}_{1}\right][69]=1$

$>\quad$ Glukosa Plasma Puasa (GPP)

$\mu_{\text {GPPrendah }}\left[\mathrm{x}_{2}\right][61]=1$

$\mu_{\text {GPPsedang }}\left[\mathrm{x}_{2}\right][61]=0$

$\mu_{\mathrm{GPP} \text { tinggi }}\left[\mathrm{x}_{2}\right][61]=0$

$\mu_{\text {GPPsangattinggi }}\left[\mathrm{x}_{2}\right][61]=0$

> Glukosa Plasma Tidur (GPT)

$\mu_{\mathrm{GPTrendah}}\left[\mathrm{x}_{3}\right][105]=1$

$\mu_{\text {GPTsedang }}\left[\mathrm{x}_{3}\right][105]=0$

$\mu_{\text {GPTtinggi }}\left[\mathrm{x}_{3}\right][105]=0$

Glukosa Darah 2 jam PP (GD) 
$\mu_{\mathrm{GPPrendah}}\left[\mathrm{x}_{4}\right][109]=0$

$\mu_{\text {GPPsedang }}\left[\mathrm{x}_{4}\right][109]=1$

$\mu_{\text {GPPtinggi }}\left[\mathrm{x}_{4}\right][109]=0$

$\mu_{\text {GPPsangattinggi }}\left[\mathrm{x}_{4}\right][109]=0$

Kadar $\mathrm{HbA} 1 \mathrm{c}$

$\mu_{\text {HbAlcrendah }}\left[\mathrm{x}_{5}\right][6]=0$

$\mu_{\text {HbAlcsedang }}\left[\mathrm{x}_{5}\right][6]=1$

$\mu_{\text {HbAlctinggi }}\left[\mathrm{x}_{5}\right][6]=0$

\section{Kadar HDL}

$\mu_{\text {HDLrendah }}\left[\mathrm{x}_{6}\right][50]=0$

$\mu_{\text {HDLsedang }}\left[\mathrm{x}_{6}\right][50]=1$

$\mu_{\text {HDLtinggi }}\left[\mathrm{x}_{6}\right][50]=0$

\section{Trigliserida}

$\mu_{\text {Trigliseridarendah }}\left[\mathrm{x}_{7}\right][111]=0$

$\mu_{\text {Trigliseridasedang }}\left[\mathrm{x}_{7}\right][111]=1$

$\mu_{\text {Trigliseridatinggi }}\left[\mathrm{x}_{7}\right][111]=0$

Kadar Insulin

$\mu_{\text {Insulinrendah }}\left[\mathrm{x}_{8}\right][4]=0$

$\mu_{\text {Insulinsedang }}\left[\mathrm{x}_{8}\right][4]=1$

$\mu_{\text {Insulintinggi }}\left[\mathrm{x}_{8}\right][4]=0$

Umur

$\mu_{\text {anak-anak }}\left[\mathrm{x}_{9}\right][19]=0$

$\mu_{\text {dewasa }}\left[\mathrm{x}_{9}\right][19]=\frac{19-10}{10}=0,9$

b. Aplikasi Fungsi Implikasi

[R1] IF GDP rendah AND GPTrendah THEN Negatif Diabetes

$$
\begin{gathered}
\alpha-\text { Predikat }_{1}=\min \left(\mu_{\text {GDPrendah,GPTrendah }}\right) \\
=\min (1 ; 1)=1
\end{gathered}
$$

[R2] IF GDPrendah AND GPPrendah THEN Negatif Diabetes

$\alpha-$ Predikat $_{1}=\min \left(\mu_{\mathrm{GDPrendah}, \mathrm{GPPrendah}}\right)$

$$
=\min (1 ; 1)=1
$$

[R3] IF GDPrendah AND GD rendah THEN Negatif Diabetes

$$
\begin{gathered}
\alpha-\text { Predikat }_{1}=\min \left(\mu_{\text {GDPrendah,GDrendah }}\right) \\
=\min (1 ; 0)=0
\end{gathered}
$$

[R4] IF GDPrendah AND HDLsedang THEN Negatif Diabetes

$$
\begin{gathered}
\alpha-\text { Predikat }_{1}=\min \left(\mu_{\text {GDPrendah }, \text { HDLsedang }}\right) \\
=\min (1 ; 1)=1
\end{gathered}
$$

[R5] IF GDPrendah AND HbAlcrendah THEN Negatif Diabetes

$$
\begin{gathered}
\alpha-\text { Predikat }_{1}=\min \left(\mu_{\text {GDPrendah,HbAlcrendah }}\right) \\
=\min (1 ; 0)=0
\end{gathered}
$$

[R6] IF GDP rendah AND Tg rendah THEN Negatif Diabetes

$\alpha-$ Predikat $_{1}=\min \left(\mu_{\mathrm{GDPrendah}, \text { Tgrendah }}\right)$

$$
=\min (1 ; 0)=0
$$


[R7] IF GDP rendah AND Insulin sedang THEN Negatif Diabetes

$$
\begin{gathered}
\alpha-\text { Predikat }_{1}=\min \left(\mu_{\mathrm{GDPrendah}, \text { Insulinsedang }}\right) \\
=\min (1 ; 1)=1
\end{gathered}
$$

[R8] IF GPTrendah AND GPPrendah THEN Negatif Diabetes

$$
\begin{gathered}
\alpha-\text { Predikat }_{1}=\min \left(\mu_{\text {GPTrendah,GPPrendah }}\right) \\
=\min (1 ; 1)=1
\end{gathered}
$$

[R9] IF GPT rendah AND GD rendah THEN Negatif Diabetes

$\alpha-$ Predikat $_{1}=\min \left(\mu_{\mathrm{GPT} \text { rendah,GDrendah }}\right)$

$$
=\min (1 ; 0)=0
$$

[R10] IF GPTrendah AND HDLsedang THEN Negatif Diabetes

$$
\begin{gathered}
\alpha-\text { Predikat }_{1}=\min \left(\mu_{\text {GPTrendah } \left._{\text {HDLsedang }}\right)}\right) \\
=\min (1 ; 1)=1
\end{gathered}
$$

[R11] IF GPTrendah AND HbA1c rendah THEN Negatif Diabetes

$$
\begin{gathered}
\alpha-\text { Predikat }_{1}=\min \left(\mu_{\mathrm{GPT} \text { rendah,HbAlcrendah }}\right) \\
=\min (1 ; 0)=0
\end{gathered}
$$

[R12] IF GPTrendah AND Tgrendah THEN Negatif Diabetes

$$
\begin{gathered}
\alpha-\text { Predikat }_{1}=\min \left(\mu_{\text {GPTrendah,Tgrendah }}\right) \\
=\min (1 ; 0)=0
\end{gathered}
$$

[R13] IF GPT rendah AND Insulin sedang THEN Negatif Diabetes

$$
\begin{gathered}
\alpha-\text { Predikat }_{1}=\min \left(\mu_{\text {GPTrendah,insulinsedang }}\right) \\
=\min (1 ; 1)=1
\end{gathered}
$$

[R14] IF GPP rendah AND GD rendah THEN Negatif Diabetes

$$
\begin{gathered}
\alpha-\text { Predikat }_{1}=\min \left(\mu_{\text {GPPrendah,GDrendah }}\right) \\
=\min (1 ; 0)=0
\end{gathered}
$$

[R15] IF GPPrendah AND HDLsedang THEN Negatif Diabetes

$$
\begin{gathered}
\alpha-\text { Predikat }_{1}=\min \left(\mu_{\text {GPPrendah }, \text { HDLsedang }}\right) \\
=\min (1 ; 1)=1
\end{gathered}
$$

[R16] IF GPPrendah AND HbA1c rendah THEN Negatif Diabetes

$$
\begin{gathered}
\alpha-\text { Predikat }_{1}=\min \left(\mu_{\text {GPPrendah,HbAlcrendah }}\right) \\
=\min (1 ; 0)=0
\end{gathered}
$$

[R17] IF GPPrendah AND Tgrendah THEN Negatif Diabetes

$$
\begin{gathered}
\alpha-\text { Predikat }_{1}=\min \left(\mu_{\text {GPPrendah,Tgrendah }}\right) \\
=\min (1 ; 0)=0
\end{gathered}
$$

[R18] IF GD rendah AND HDLsedang THEN Negatif Diabetes

$$
\begin{gathered}
\alpha-\text { Predikat }_{1}=\min \left(\mu_{\text {GDrendah }, \text { HDLsedang }}\right) \\
=\min (0 ; 1)=0
\end{gathered}
$$

[R19] IF GDrendah AND HbA1c rendah THEN Negatif Diabetes

$$
\begin{gathered}
\alpha-\text { Predikat }_{1}=\min \left(\mu_{\mathrm{GDrendah}, \mathrm{Hb} \text { Alcrendah }}\right) \\
=\min (0 ; 0)=0
\end{gathered}
$$

[R20] IF GDrendah AND Tgrendah THEN Negatif Diabetes

$$
\begin{gathered}
\alpha-\text { Predikat }_{1}=\min \left(\mu_{\text {GDrendah, }}\right. \text {,grendah } \\
=\min (0 ; 0)=0
\end{gathered}
$$

[R21] IFHbA1c rendah AND HDLsedang THEN Negatif Diabetes

$$
\begin{gathered}
\alpha-\text { Predikat }_{1}=\min \left(\mu_{\text {HbAlcrendah,HDLsedang }}\right) \\
=\min (0 ; 1)=0
\end{gathered}
$$


[R22] IF HbA1crendah AND Tgrendah THEN Negatif Diabetes

$$
\begin{gathered}
\alpha-\text { Predikat }_{1}=\min \left(\mu_{\text {HbAlcrendah,Tgrendah }}\right) \\
=\min (0 ; 0)=0
\end{gathered}
$$

[R23] IF GDP sedang AND GPT sedang THEN Pradiabetes

$$
\begin{gathered}
\alpha-\text { Predikat }_{1}=\min \left(\mu_{\text {GDPsedang,GPTsedang }}\right) \\
=\min (0 ; 0)=0
\end{gathered}
$$

[R24] IF GDP sedang AND GPP sedang THEN Pradiabetes

$$
\begin{gathered}
\alpha-\text { Predikat }_{1}=\min \left(\mu_{\text {GDPsedang,GPPsedang }}\right) \\
=\min (0 ; 0)=0
\end{gathered}
$$

[R25] IF GDP sedang AND GD tinggi THEN Pradiabetes

$$
\begin{gathered}
\alpha-\text { Predikat }_{1}=\min \left(\mu_{\text {GDPsedang,GDtinggi }}\right) \\
=\min (0 ; 0)=0
\end{gathered}
$$

[R26] IF GDP tinggi AND Insulin rendah THEN Positif Diabetes Tipe 1

$$
\begin{gathered}
\alpha-\text { Predikat }_{1}=\min \left(\mu_{\mathrm{GDP} \text { tinggi, insulinrendah }}\right) \\
=\min (0 ; 0)=0
\end{gathered}
$$

[R27] IF GDP sangat tinggi AND Insulin rendah THEN Positif Diabetes Tipe 1

$$
\begin{gathered}
\alpha-\text { Predikat }_{1}=\min \left(\mu_{\text {GDPsangattinggi,insulinrendah }}\right) \\
=\min (0 ; 0)=0
\end{gathered}
$$

[R28] IF Umur Anak AND Insulin rendah THEN Positif Diabetes Tipe 1

$$
\begin{gathered}
\alpha-\text { Predikat }_{1}=\min \left(\mu_{\text {umuranak,insulinrendah }}\right) \\
=\min (0 ; 0)=0
\end{gathered}
$$

[R29] IF HbA1c tinggi AND Insulin rendah THEN Positif Diabetes Tipe 1

$$
\begin{gathered}
\alpha-\text { Predikat }_{1}=\min \left(\mu_{\mathrm{HbAlctinggi}, \text { insulinrendah }}\right) \\
=\min (0 ; 0)=0
\end{gathered}
$$

[R30] IF Umur Dewasa AND GDP tinggi THEN Positif Diabetes Tipe 2

$$
\begin{gathered}
\alpha-\text { Predikat }_{1}=\min \left(\mu_{\text {umurdewasa,GDPtinggi }}\right) \\
=\min (0,9 ; 0)=0
\end{gathered}
$$

[R31] IF GDP sangat tinggi AND HDL rendah THEN Positif Diabetes Tipe 2

$$
\begin{gathered}
\alpha-\text { Predikat }_{1}=\min \left(\mu_{\text {GDPsangattinggi,HDLrendah }}\right) \\
=\min (0 ; 0)=0
\end{gathered}
$$

[R32] IF HbA1c tinggi AND HDL rendah THEN Positif Diabetes Tipe 2

$$
\begin{gathered}
\alpha-\text { Predikat }_{1}=\min \left(\mu_{\text {HbAlctinggi,HDLrendah }}\right) \\
=\min (0 ; 0)=0
\end{gathered}
$$

[R33] IF HbA1c tinggi AND Tg tinggi THEN Positif Diabetes Tipe 2

$$
\begin{gathered}
\alpha-\text { Predikat }_{1}=\min \left(\mu_{\text {HbAlctinggi,Tgtinggi }}\right) \\
=\min (0 ; 0)=0
\end{gathered}
$$

\section{c. Defuzzifikasi (Defuzzification)}

$\begin{array}{ll}\text { Indeks Negatif Diabetes } & =0,2 \\ \text { Indeks Pradiabete } & =0,4 \\ \text { Indeks Positif Diabetes tipe- } 1 & =0,8 \\ \text { Indeks Positif Diabetes tipe-2 } & =0,6\end{array}$ 
Pada Metode Sugeno defuzzifikasi dilakukan dengan Weighted Awerage (WA), maka penentuan resiko penyakit Diabetes Mellitus

$$
z^{*}=\frac{(1 * 0,2)+(1 * 0,2)+(1 * 0,2)+(1 * 0,2)+(1 * 0,2)+(1 * 0,2)+(1 * 0,2)+(1 * 0,2)}{8}=0,2
$$

Kesimpulan Pasien tersebut Negatif Diabates

d. Menentukan Tingkat Resiko Penyakit DM Menggunakan MATLAB

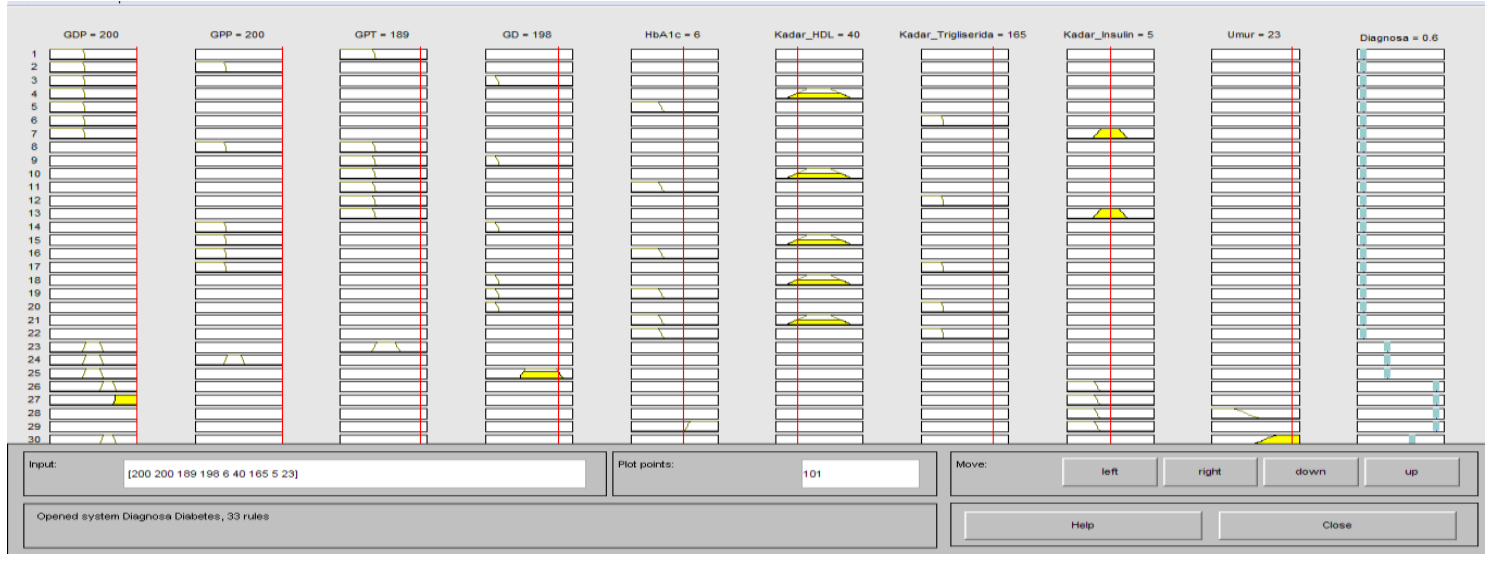

Gambar 1 : FIS Editor

\subsection{Pembahasan}

Untuk menentukan tingkat resiko penyakit Diabetes Mellitus seorang pasien, logika Fuzzy dengan metode Sugeno menggunakan empat tahapan proses setelah pengambilan data. Data yang diperoleh dari hasil wawancara terlebih dahulu ditentukan variabel beserta fungsi keanggotaannya. Kemudian setelah itu membuat aturan Fuzzy berdasarkan kombinasi himpunan Fuzzy dari variabel yang telah ditentukan sebelumnya. Langkah selanjutnya adalah membuat implikasi fungsi dan komposisi aturan. Langkah terakhir adalah mendapatkan penegasan (defuzzyfikasi) dari daerah hasil komposisi setiap aturan yang diperoleh.

Hasil yang diperoleh dari penelitian ini adalah menentukan apakah seorang pasien terindikasi memiliki penyakit Diabetes Mellitus yang dibagi dalam 4 kelas, yaitu, Negatif Diabetes Mellitus, Pradiabetes, Diabetes tipe-1, dan Diabetes tipe-2, yang sebelumnya sudah dijelaskan masingmasing kriterianya. Untuk menentukan tingkat resiko penyakit Diabetes Mellitus maka dilakukan perhitungan hasil laboratorium, pasien yang diperoleh dari RSUD Undata Palu, Sulawesi Tengah.

Dalam penelitian ini, telah diambil data atau sampel sebanyak 10 orang pasien yang masingmasing memiliki gejala tertentu (Lihat lampiran data pasien). Sehingga dengan menggunakan proses analisis data diatas, maka di dapatkan hasil yang hampir sama dengan prediksi dokter, yang terdapat pada Tabel 3. 
Tabel 3 : Perbandingan Hasil Perhitungan Menggunakan Matlab dengan Hasil Diagnosa Dokter

\begin{tabular}{|c|c|c|c|}
\hline No & Pasien & Prediksi Dokter & $\begin{array}{c}\text { Prediksi DM menggunakan FIS } \\
\text { dengan Metode Sugeno }\end{array}$ \\
\hline 1 & $y_{1}$ & Positif DM tipe-2 & Positif DM tipe-2 \\
\hline 2 & $y_{2}$ & Pradiabetes & Pradiabetes \\
\hline 3 & $y_{3}$ & Negatif DM & Pradiabetes \\
\hline 4 & $y_{4}$ & Pradiabetes & Positif DM tipe-2 \\
\hline 5 & $y_{5}$ & Positif DM tipe-2 & Negatif DM \\
\hline 6 & $y_{6}$ & Negatif DM & Negatif DM \\
\hline 7 & $y_{7}$ & Hipertensi & Negatif DM \\
\hline 8 & $y_{8}$ & Demam Berdarah & Positif DM tipe-2 \\
\hline 9 & $y_{9}$ & Hipertensi & \\
\hline 10 & $y_{10}$ & Positif DM tipe-2 & \\
\hline
\end{tabular}

\section{Kesimpulan}

Berdasarkan hasil dan pembahasan sebelumnya, maka dapat ditarik kesimpulan bahwa dengan menggunakan metode inferensi Fuzzymodel Sugeno diperoleh hasil yang sama antara hasil pehitungan MATLAB dengan hasil perhitungan manual. Dari ke-10 sampel pasien, ada 6 pasien yang Negatif DM, 1 pasien Pradiabetes dan 3 Pasien yang Negatif DM. Faktor utama penyebab terjadinya tingkat resiko penyakit DM pada pasien tersebut adalah Gula Darah Puasa yang tinggi.

\section{Daftar Pustaka}

[1]. Darmono. 2005. Pengaturan Pola Hidup Penderita Diabetes Untuk Mencegah Komplikasi Kerusakan Organ-Organ Tubuh. Semarang: Universitas Diponegoro.

[2]. http://www.detikNews.com/IndeksBerita/10.htm. Indonesia Negara ke-4 Penyandang Diabetes Terbanyak. 24 Desember 2012

[3]. Soegondo, Sidartawan, dkk. 2004, Penatalaksanaan Diabetes Melitus Terpadu, Jakarta: Balai Penerbit Fakultas Kedokteran Universitas Indonesia.

[4]. Sudoyo, Aru W, dkk. 2006, IImu Penyakit Dalam, Jilid 3, Edisi 4, Jakarta: Pusat Penerbitan Departemen Ilmu Penyakit Dalam Fakultas Kedokteran Universitas Indonesia. 